\title{
2 Vocal Culture in the Age of Laryngoscopy
}

BENJAMIN STEEGE

For several months beginning in 1884, readers of Life, Science, Health, the Atlantic Monthly and similar magazines would have encountered half-page advertisements for a newly patented medical device called the 'ammoniaphone' (Figure 2.1). Invented and promoted by a Scottish doctor named Carter Moffat and endorsed by the soprano Adelina Patti, British Prime Minister William Gladstone and the Princess of Wales, the ammoniaphone promised a miraculous transformation in the voices of its users. It was recommended for 'vocalists, clergymen, public speakers, parliamentary men, readers, reciters, lecturers, leaders of psalmody, schoolmasters, amateurs, church choirs, barristers, and all persons who have to use their voices professionally, or who desire to greatly improve their speaking or singing tones.' Some estimates indicated that Moffat sold upwards of 30,000 units, yet the ammoniaphone was a flash in the pan as far as such things go, fading from public view after $1886 .{ }^{2}$ If this forgotten object is an apt point of departure for a chapter on what might be described as the moral imagination of Victorian voices, that is because it so effectively draws attention to certain fantasies of the vocal self playing out across a broader public discourse at this time.

The ammoniaphone was elegantly simple in design (and, despite its name, soundless): it was a species of inhaler consisting of 'a tube about 25 inches long, constructed of a specially prepared non-corrosive metal, with handles, having patent spring valves'. The tube was 'charged with a chemical compound, combined so as to resemble in effect that which is produced by the SOFT BALMY air of the Italian Peninsula when inhaled into the lungs, hence the term - ARTIFICIAL ITALIAN AIR'. ${ }^{3}$ What one observer referred to as 'the harsh sputterings and cacklings of our Northern throats' might be softened by inhaling its vapour of hydrogen peroxide, a little ammonia and various other chemicals, which were supposed to approximate the soothing and invigorating properties of the atmosphere

An earlier version of this chapter was presented at 'Performing Voices: Between Embodiment and Mediation', a conference at the American Academy in Rome in collaboration with the Max Planck Institute for the History of Science, December 2009. I thank David Trippett and Benjamin Walton for their insightful critiques as I prepared the present version.

1 [unsigned] 1885b, 27. ${ }^{2}$ [unsigned] 1899, 1:392. ${ }^{3}$ [unsigned] 1885a, viii. 


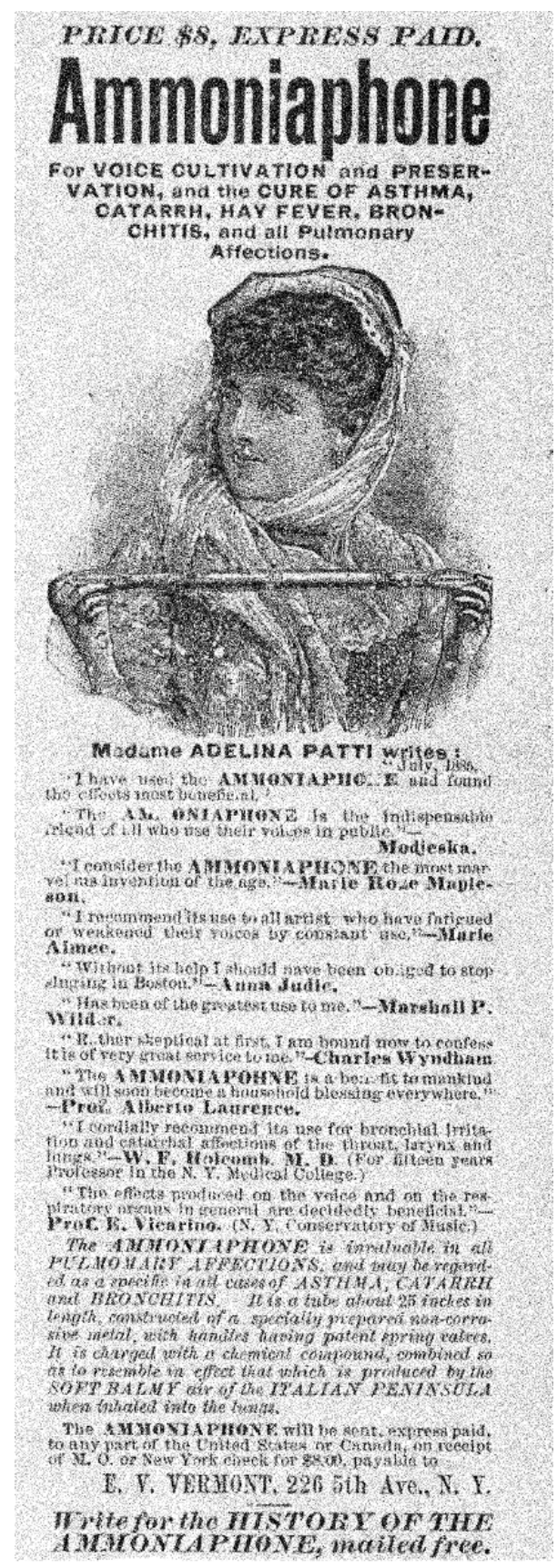

Figure 2.1 'Ammoniaphone', Life, 7, 159 (14 January 1886), p. 43. 


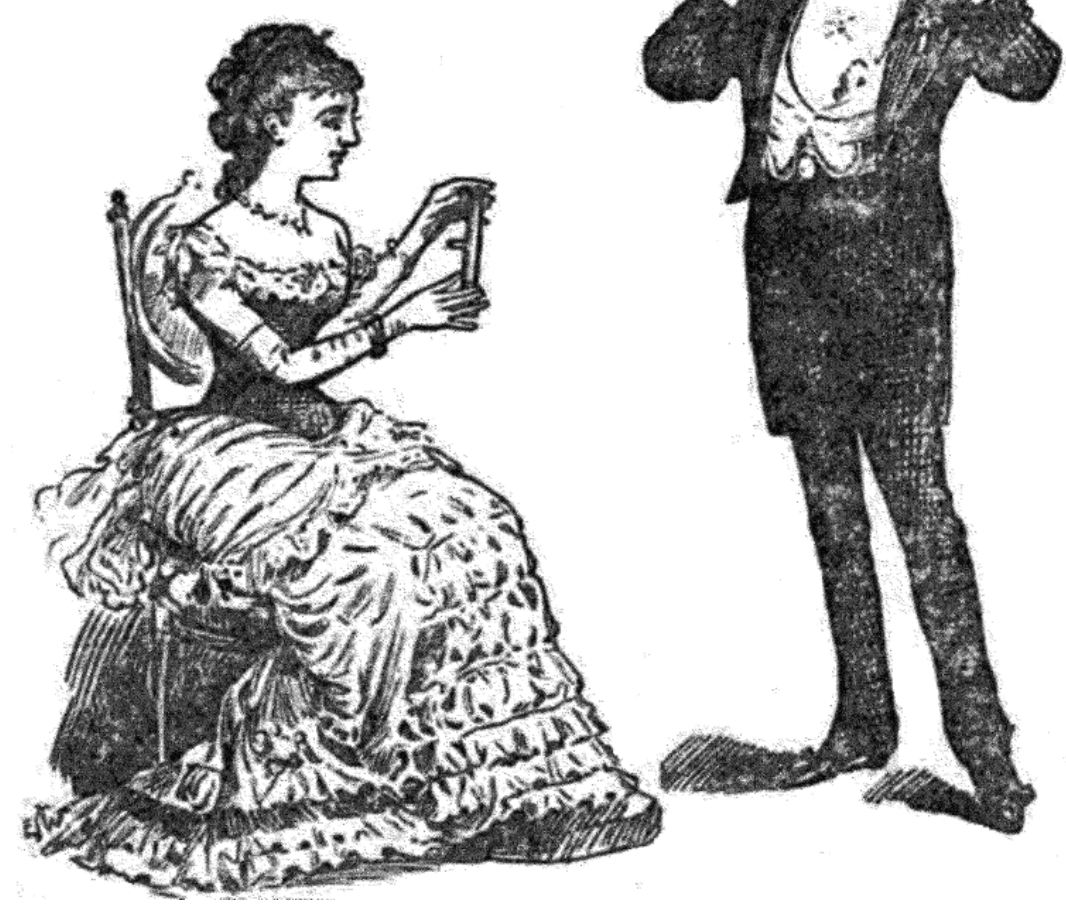

Figure 2.2 Health, 3, 74 (5 September 1884), p. 351.

breathed by so many prominent Italian singers and, before them, Roman orators. ${ }^{4}$ Figure 2.2 shows an advertisement depicting two people in evening dress putting the instrument to their lips as if playing a piccolo, while in fact the airflow went in the reverse direction. 'Thus, by means of chemical science we are brought into a fairy land of which no one knows the extent. We can have as it were Italian air laid on at our own doors. ${ }^{5}$

\footnotetext{
${ }^{4}$ Mackenzie [1886] 1891, 157; but note that Mackenzie, a respected laryngologist, judged the apparatus in the negative: 'Any real effect which it may have is of a highly stimulant nature; of its powerful influence on the imagination, however, there can be no doubt' (159). That ammonia is a corrosive chemical with considerable potential for damage to the internal organs was evidently unknown at the time.

5 Bowick 1884, 123.
} 
The ammoniaphone's working principle suggests more than just a belief in environmental determinism - the conceit that the superiority of Italian vocal art was due principally to climatic factors - but also a sense that one's voice might be transposed from another place, 'inspired' according to the literal etymology of the term. Inhaling the ammonia vapour was like taking breath from elsewhere into one's own person, conjuring a sense of vocal self out of thin air. Furthermore, it suggests that by laying claim to this foreign breath - 'Italianising' the voice, as it was said - one might not simply become a better vocalist but in fact be healed and made whole. Hygiene and musicality overlap here in a convergence characteristic of the era. The ammoniaphone typifies a generational fever for a wide variety of self-administered techniques of bodily care, attesting to a morality that might be described as equally self-glorifying and selfdenying: self-glorifying because it encouraged absorption in one's own aesthetic self, self-denying because the instrument's conception derogated the sensation of the user's own personhood in relation to some projected space or thing beyond the person. The ammoniaphone capitalised on the suspicion that value comes from a fantasised attachment to a 'not here', a certain dimly imagined spatial dislocation. In facilitating a fascination with the inward vocal self only through an intermediary external element, the device set up a dynamic in which the self is made by being made strange.

The ammoniaphone is thus an emblem of a particularly anxious moment in the history of the voice. The Victorian nineteenth century, and especially the decades after 1870, witnessed a marked surge in amateur obsession with various acts of vocalising (and not only, or even primarily, in the performance contexts most familiar to music historians). ${ }^{6}$ Faced with the burgeoning market for instruction manuals on what was called 'vocal culture', it is not difficult to assent to Steven Connor's comment on the period that 'a generalised cultural engorgement of the idea of the voice suggested and produced as much nervousness as it did exultation'?

Nor is it difficult to sympathise with George Bernard Shaw's condescension toward this phenomenon in an 1886 sketch of the relevant cultural milieu:

\footnotetext{
6 The culture of domestic theatre is relevant here; see Cobrin 2006 and Meeuwis 2012.

7 Connor 2000, 332. The steady stream of such manuals would include Urling 1857, Atwell 1868, Monroe 1869, Barnes 1874, Lunn [1874] 1900, E. Seiler 1875, 1884, Barraclough 1876, Thwing 1876, Holmes 1879, Sandlands 1886, Mackenzie [1886] 1891, Myer 1891 and Aikin 1900 .
} 
Though there must by this time be in existence almost as many handbooks for singers and speakers as a fast reader could skip through in a lifetime or so, publishers still find them safe investments. Young people who are born into the fringe of the musical and theatrical professions from which we draw our great stock of deadheads are generally much at a loss when the question of earning a living comes home to them ... Their ineptly stagy manners and appearance, like their morals, are the impress of an environment of bismuth and rouge, overcoats with Astrakhan collars, moustaches, sham concerts for the benefit of sham singers out of engagement, and an atmosphere which creates an unquenchable craving for admission without payment to all sorts of public entertainments, especially to the Opera.... Unsuspicious of their own futility, they have some distorted ideas of practice, but none of study. They are always in search of a method - especially the old Italian one of [Nicola] Porpora; and they will even pay cash for a handbook of singing, a set of unintelligible photographs of the larynx, or an ammoniaphone from which to suck a ready-made compass of three octaves with the usual fortune attached. ${ }^{8}$

Harping on a commercialism targeting dilettantes, Shaw reacts to the emergence of cultural forces - the market and the popular, in an adolescent phase of what would later come to be known derogatorily as the 'culture industry' - which still bore the added threat of a relative novelty that has long since worn off. His immediate concern is with the easily discreditable notion of a short cut to artistry. It is the extreme temporality of the market, exemplified by the scarcely two-year lifespan of the ammoniaphone itself, that denies the possibility of a more genuine 'practice' and forsakes anything so sustained and invested as 'study'. But it is also worth noticing how thoroughly Shaw's scene is pervaded by an insistent staging of the self, both in the local sense of simply acquiring 'stagy manners', and also in the more expansive sense of seeking techniques for constructing a persona through which one might activate oneself as an agent of public action in the first place. Despite his intentions, Shaw's critical-anthropological impulse does not appear to prepare a principle for drawing the line between appearance and reality, between the superficial activity of acquiring manners and the more durable disposition toward becoming capable of entering vocally into the world at all.

Beyond the optimistic promises of a 'ready-made' substitute for bel canto technique, the ongoing communal project of developing (strengthening, smoothing, curing) the voice was persistently nagged by a set of challenges that might be described as problems of self-observation. The

${ }^{8}$ Shaw, in Tyson 1991, 164-5. 
voice had so often been described, perhaps most familiarly by Augustine, as that non-object which exemplified the fleeting and the insubstantial. ${ }^{9}$ How, then, might one make even one's own voice present to oneself, in order to 'fix' its qualities, both in the sense of improving inadequacies and also in the sense of stabilising, maintaining and, especially, holding-before-oneself for observation? The ammoniaphone answered these questions by shortcircuiting them: denying the problem of self-observation by giving the appearance that voice could be acquired from without. At roughly the same historical moment, though, another medical-cultural object approached the problem from a different angle, making the voice in some sense present by making it visible. This object was the laryngoscope, originally a clinical instrument, which came to occupy a central, if disputed, place in vocal pedagogy by 1870 . Its story, along with that of one of its most fervent devotees, follows. What this episode demonstrates, I suggest, is simply how that initial orientation toward fixity or stability in the voice is increasingly frustrated by the very techniques adopted to accomplish it. Put somewhat differently (and more theoretically), the episode turns out to be an instance where efforts at naturalisation invert into a kind of defamiliarisation that arguably affiliates these practices with an experience of modernism more broadly conceived.

Even in more respectable niches of vocal pedagogy and clinical practice, the force exerted by Dr Moffat's Italian fantasy was strongly felt. In many Northern European accounts of vocal culture, narratives of cultural-historical decline spurred the ambition of returning the voice to a supposedly more natural state associated with Italy in the eighteenth century. This impulse overwhelmingly determined the rhetorical trajectory of writing by Emma Seiler (1821-1886), a German voice teacher later active in North America, who rehearsed the declinist motif with a sense of personal urgency informed by her experiences as a vocal student in Dresden in the 1850s. Finding her own voice ruined at the age of thirty by the harsh pedagogy of an unnamed teacher, Seiler sought to ameliorate the crisis by taking up the study of vocal anatomy, an endeavour for which she was particularly well prepared as the daughter of the court physician to King Ludwig of Bavaria, sister-in-law of two surgeons, wife of another doctor, and (later) mother of a leading American laryngologist. ${ }^{10}$ But her account of personal efforts to reverse the damage to her vocal organs was couched

\footnotetext{
9 Augustine, Confessions, book XI, section 27.

10 For Seiler's biography, see [unsigned] 1891, 149-62, esp. 151-4; and [unsigned] 1893, 591-2. For a recent evaluation of her pedagogy, see Price 2011. For her son's work, see C. Seiler 1883, whose first chapter treats, appropriately enough, 'The Laryngoscope' (13-26).
} 
in terms that expanded into a broader historical vision. The injury to Seiler's own throat, we are meant to infer from her writings, ontogenetically recapitulated a pattern of degradation of the European voice that had been phylogenetically underway for several generations already. Seiler's 1861 treatise on vocal pedagogy, Altes und Neues über die Ausbildung des Gesangorganes (published in English in 1868 as The Voice in Singing), nostalgically invoked a golden age of mid-eighteenth-century Italian singing - the era of Porpora and Farinelli - and blamed the comparatively poor state of current practice on a number of historical factors, including the disappearance of the male soprano, the decentralisation and regionalism of pedagogy and theory, and the broader democratisation of musical culture manifest in her era's 'dilettantism without precedent'. Voice teachers from one town to the next hawked idiosyncratic methods without any unified code of knowledge to distinguish quacks from masters. The castrato's historical extinction, moreover, expedited the disunification of vocal practice, for that now lost figure, Seiler suggested, had once united in a single body a quasi-hermaphroditic knowledge of the voices of both sexes. ${ }^{11}$

An insistence on empirical understanding was central to Seiler's project. It was a perceptual intuition of the heard voice, the act of learning through direct imitation, that had distinguished singers of the old Italian school, which she credited with an 'unclouded gift for observation' and a selfawareness and centredness that had been forsaken in the intervening generations. $^{12}$

The old Italian method of instruction, to which vocal music owed its high condition, was purely empirical, i.e. the old singing masters taught only according to a sound and just feeling for the beautiful, guided by that faculty of acute observation, which enabled them to distinguish what belongs to nature. The pupils learned by imitation, as children learn their mother tongue, without troubling themselves about rules. But after the true and natural way has once been forsaken, and for so long a period only the false and the unnatural has been heard and taught, it seems almost impossible by empiricism alone to restore the old and proper method of teaching. ${ }^{13}$

Yet this lost, quasi-Goethean 'gift' of intuitive perception - along with the imagined presentness and transparency to the observer it assumed - could only be replaced by something proper to the modern era: in this case, methods and techniques of anatomical and physiological observation, of

\footnotetext{
11 E. Seiler 1884, 28-9. Related material was serialised as E. Seiler $1865 . \quad{ }^{12}$ E. Seiler 1865, 53.

13 E. Seiler 1884, 30-1.
} 
which the laryngoscope, a device for observing the movement of the vocal cords, would come to constitute the exemplary practice. ${ }^{14}$

Moving through a series of doctors' households, Seiler did not come by her interest in anatomy and physiology out of the blue. Early in her lifelong project, she befriended a medical student who surreptitiously procured a separated throat, which they spent two weeks carefully dissecting together late at night, studying the muscular and cartilaginous structure of the vocal organ under cover of darkness (these practices were considered improper for a woman). ${ }^{15}$ Yet by the time she left Dresden, her own larynx in poor condition, Seiler no longer felt compelled to keep her anatomical interests in the dark, and outed herself as an aspiring laryngologist around the time she arrived in Heidelberg in the mid-1850s, where she established contact with several prominent scientists at the university, including the chemist Robert Bunsen, the physicist Gustav Kirchoff and, most pertinent, the physiologist Hermann von Helmholtz (1821-1894), who had just come to Heidelberg himself as part of regional reforms in medical education. ${ }^{16}$

The convergence of Seiler and Helmholtz in Heidelberg perfectly suited their respective agendas at that moment, though in rather different ways. At the time of his move, Helmholtz was turning to the study of vowel sounds from a physical acoustical perspective, and much of this research required the assistance of a trained vocalist who could sing a tone with sufficient steadiness and duration to allow sustained close attention to its qualities. 'While engaged on my book, Die Lehre von den Tonempfindungen,' Helmholtz wrote, 'I had the honour of becoming acquainted with Mad. Seiler, and of being assisted by her in my essay upon the formation of the vowel tones and the registers of the female voice. I have thus had an opportunity of knowing the delicacy of her musical ear and her ability to master the more difficult and abstract parts of the theory of music. ${ }^{, 17}$ Yet these activities were of interest primarily to Helmholtz, and only secondarily to Seiler. Helmholtz was concerned with mapping out a new disciplinary landscape of sensory physiology, one which required unprecedented degrees of control over the production and apprehension of sensory objects normally marginalised or concealed, or even perhaps non-existent for practical

14 On the Goethean 'gift' of natural observation, see Kittler 2002, 155-66.

15 [unsigned] 1891, 158.

16 [unsigned] 1893, 592. On science reforms in Heidelberg at this time, see Tuchman 1993, esp. 138-57.

17 From an 1866 letter quoted in the 'Translator's Preface' to E. Seiler 1884, 7-8. Helmholtz refers to his Die Lehre von den Tonempfindungen als physiologische Grundlage für die Theorie der Musik (1863), and 'Ueber die Klangfarbe der Vocale' (1859). 


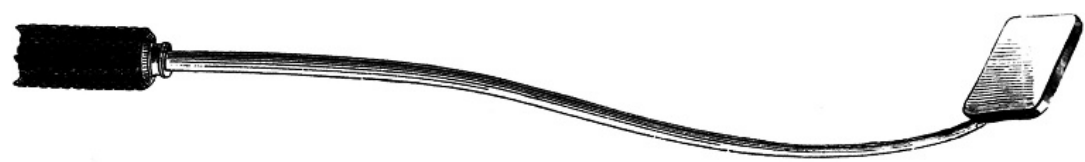

Figure 2.3 'Laryngoscope', Johann Nepomuk Czermak, Der Kehlkopfspiegel und seine Verwerthung für Physiologie und Medizin (Leipzig: Wilhelm Engelmann, 1860), p. 16.

purposes, prior to experiment. ${ }^{18}$ Though just as attuned as Helmholtz was to sensory marginalia, Seiler took interest less in the texture of new sensations for their own sake, and more in their mode of production. So it is not surprising that the element of their exchange that became magnified in her accounts of their collaboration, in contrast to his, was the practice of the laryngoscopy. This promised to render the mechanics of the voice observable with a previously unimaginable presence and force.

In 1859 , the laryngoscope was still relatively new to musical society. It had been four years since the London musical and scientific communities could have read an account by the influential voice teacher Manuel García fils (1805-1906), who is often credited with inventing the device itself. ${ }^{19}$ Yet in that initial article, García had merely offered a theory about the anatomical mode of production of the various vocal registers, without right away suggesting anything like an intervention in the actual practice of singing itself. In terms of priority in the published record, the latter more ambitious and explicitly pedagogical goal fell first to Seiler, who thus played an important (and almost always overlooked) role in drawing the laryngoscope into a broader network of musical-scientific practice. In Seiler's work, laryngoscopy is identified as a novel mode of observation which could take the place of the Italian 'gift for observation' whose loss she lamented in her singing treatise. But what sort of practice was laryngoscopy? Like the ammoniaphone, the laryngoscope was a design of elegant simplicity, consisting of a coin-sized mirror affixed to a long metal rod (Figure 2.3), which was inserted into the throat at an angle that allowed the reflection of the top of the vocal organ to become visible to the eye of a second, observing individual. Of particular interest to singers like García and Seiler were the views of the vocal ligaments (vocal cords), the arytenoid cartilages and the muscles that moved them, and above all the changing shape of the glottis, which refers to the mercurially shifting gap between the vocal ligaments (Figures 2.4 and 2.5).

18 For discussion of Helmholtz's role in this collaboration, see Steege 2012, 179-93.

19 García 1854-5, 399-410. Stark 1999, 5, 11 and 16, perpetuates the notion of García the inventor. By contrast, Davies 2014, 133-6, offers a more nuanced interpretation. 


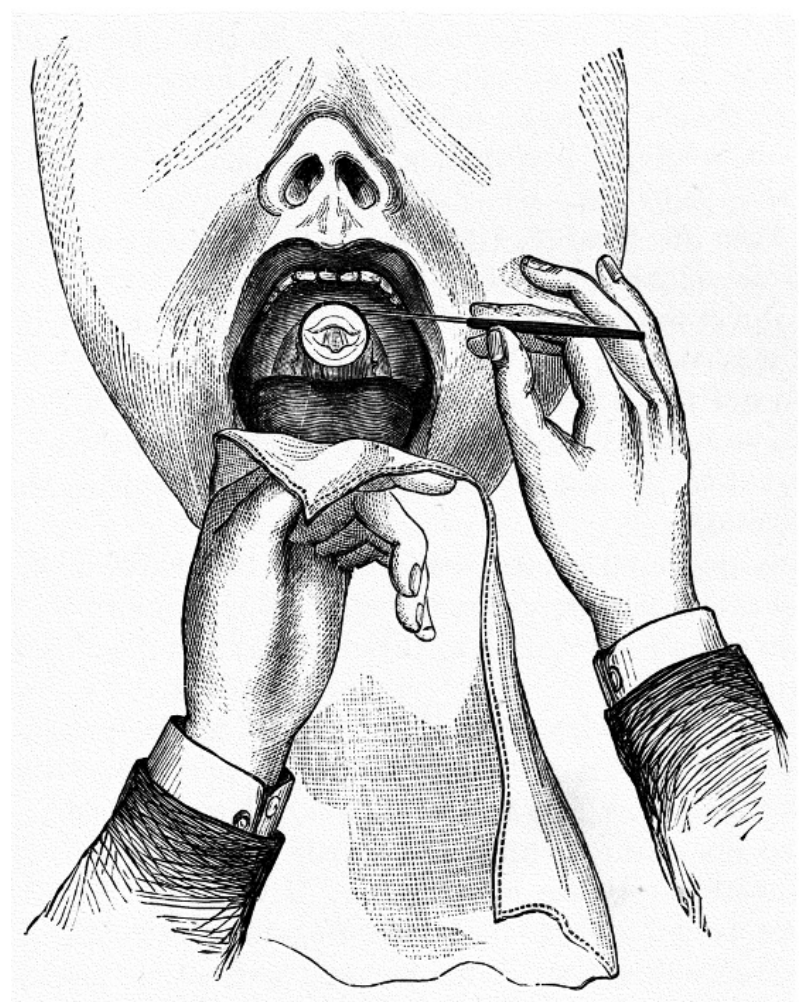

Figure 2.4 Lennox Browne, The Throat and Its Diseases, 2nd edn (Philadelphia: Lea Brothers and Co., 1887), p. 47.

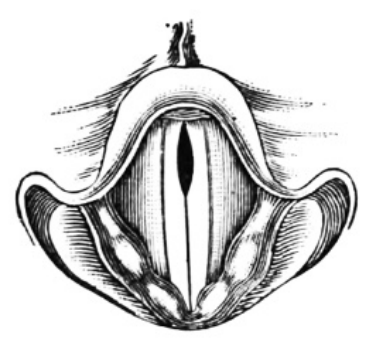

Fig. 10.-Laryngoscopic View of The Female Glottis in the Deliveiv of a Head-Note (Ordinary A ppearANCE).

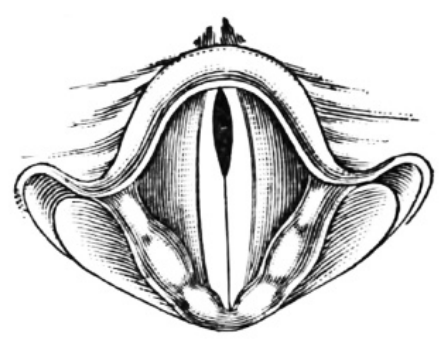

Fig. it.-LARYNGoscopic View of the Mat.e Glottis in Falsetto Singing (Ordinary Appearance).

Figure 2.5 Morell Mackenzie, Hygiene of the Vocal Organs, p. 56. 
The laryngoscope was morphologically derived from earlier variants dating to the eighteenth century. But not until around 1860 did it become an object of both sustained scientific interest and eventually public fascination. ${ }^{20}$ After the publication of Seiler's singing treatise, few manuals on the voice - whether the singing, speaking or ailing voice - failed to include illustrated discussion of how to use the laryngeal mirror and what it might teach.

Given the modesty of this object, it is not immediately clear what about it could have captured the imagination so vividly. One possibility emerges from a retrospective biographical recounting of García's first glimpse of his own vocal organ. In this initial encounter, García is alone, holding a handmirror in front of himself, a practice later known as 'autolaryngoscopy':

'During all the years of study and investigation of the problems of the voiceemission,' [García] said, 'one wish was ever uppermost in my mind - “if only I could see the glottis!"”

One day in the September of 1854, when on a visit to Paris, he was standing in the Palais Royal. Suddenly there came to him an idea. 'Why should I not try to see it?' How must this be done? Why, obviously by some means of reflection. Then, like a flash, he seemed to see the two mirrors of the laryngoscope in their respective positions as though actually before his eyes. He went straight to Charrière, the surgical instrument maker, asked whether they happened to possess a small mirror, which had been one of the failures of the London Exhibition of 1851. He bought it for six francs.

Returning home, he placed against the uvula this little piece of glass, which he had heated with warm water and carefully dried. Then with a hand-mirror he flashed on to its surface a ray of sunlight. By good fortune he hit upon the proper angle at the very first attempt. There before his eyes appeared the glottis, wide open and so fully exposed that he could see a portion of the trachea. So dumbfounded was he that he sat down aghast for several minutes. On recovering from his amazement he gazed intently for some time at the changes which were presented to his vision while the various tones were being emitted. From what he witnessed it was easy to conclude that his theory, attributing to the glottis alone the power of engendering sound, was confirmed, and thence it followed that the different positions taken by the larynx in the front of the throat had no action whatever in the formation of the sound. At last he tore himself away, and wrote a description of what he had seen. ${ }^{21}$

${ }^{20}$ García was perhaps the most influential singing teacher of the nineteenth century, numbering soprano Jenny Lind ('The Swedish Nightingale') and baritone Julius Stockhausen among his students. For a biography by the son of one his students, see Mackinlay 1908. Stark (1999, 3-32) offers a less hagiographic account.

21 Mackinlay 1908, 203-5. 
The simple immediate lesson taken from García's work was just that the position of the larynx - the bobbing up and down of the 'Adam's apple' - did not independently determine pitch and timbre, whereas the changing shape of the glottis now came to play a larger role in explaining these two phenomena. His novel attention to that strangely vacant organ, which is in fact not an autonomous organic tissue at all but an empty space between organs, would initially appear to constitute the unique significance of the event. But on a narrative-rhetorical level, the image of García dumbstruck by the very image of the glottis merits some comment. To be 'dumbfounded', as per the biographer's account, is understood here to be a silencing, which, while not absolutely paradoxical in this scene, is at least faintly ironic. The image of the open glottis, the origin of vocal tone, is itself what renders him silent. Following a moment of mute amazement, the shocking image of his own open gullet etched into his memory, García resumes singing with the mirror. The action of 'gazing', typically or at least poetically one of soundless rapture, implicitly sounds here, but the prose account, deferring to mute contemplation, tells us nothing more than that 'various tones [were] emitted', which leaves the object of hearing ambiguous (via an ambivalent 'passive voice', moreover): is García changing the pitch of his voice? the vowel quality? the intensity? In any event, he does not appear to be primarily listening, but rather looking. As the nature of the vocal object changes, García moves from being initially blind to the voice, to being mute, to ending up in a certain sense deaf.

The difficulty of coordinating a simultaneity of singing, hearing and seeing bespeaks the perceptual and somatic disjointedness of laryngoscopy generally. Later commentators reiterated in various ways the uneasy coexistence of perceptual registers, complaining for example that the voice, ideally, is 'necessarily invisible', and that to try thinking of it as something visible either misrecognises its nature or at least distracts singers from some more essential way of perceiving themselves singing. ${ }^{22}$ Against the modest frenzy that arose around the new pedagogical device, one detractor insisted:

Never use the laryngoscope. The function of this instrument is to guide the surgeon's hand and probang, and finishes there. Singing is not a question of how a distorted throat looks in an oblique mirror, but how it sounds to a healthy ear. It is not a question of optics, but one of acoustics. Many modern writers have

22 See, for example, Abbott 1924, 932 (along with the preceding and succeeding series of letters to the editor). 
deceived themselves and their readers on this point. As Wordsworth says: 'Avaunt, this vile abuse of pictured page! / Must eyes be all in all, the tongue and ear nothing? ${ }^{\text {23 }}$

A common alternative to the laryngoscope - one involving not so much direct empirical observation as indirect metaphorical action - was for vocal teachers to appeal to the manipulation of a phantasmal vocal object in an imagined space. Thus, for example: 'to focus the sound; to direct the voice towards the roof of the mouth; against the hard palate; against the upper front teeth; into the head; to the bottom of the chest; to lean the tone against the eyes! to sing all over the face! ${ }^{24}$ But laryngoscopists considered such metaphorical manipulations either too vague to be helpful, or in outright contradiction with themselves. In contrast, the perceived value of the mirror was its demystifying potential to bring imagined and real movements into accord. And yet, as I have been suggesting, the instrument itself hardly paved a clear path to the kind of immediate perception it was held to promise. Even García did not find the laryngoscope especially useful over the duration of a course of training, though he felt that it might serve as an effective propaedeutic, either for the teacher or for the student. In fact, García expressly acknowledged that there was little point in practising song with a mirror in the throat. ('If it is used under the pretence that it can show how one must sing while the throat is opened in phonation, it is clearly an instrument of torture, and deserves to be thrown away without hesitation. ${ }^{25}$ ) Rather, its value came in creating the possibility of a self-consciousness unavailable by other means. Once the visual image of the organ was lodged in the memory, knowledge of how to manipulate it effectively would theoretically follow in the same way that one might imagine visualising one's little toe moving before becoming actually capable of wiggling it.

While García, an icon of bel canto pedagogy, remains to this day linked to the singular event of the mythicised origin of laryngoscopy, one might argue (speculatively) that Seiler was substantially responsible for its popularisation. ${ }^{26}$ Her treatise, revised and expanded in English after her move to Philadelphia in 1866 and perhaps more widely read in translation than in the original German, set the precedent for subsequent writings that highlighted this new way of perceiving the activity of vocalisation. Where

23 Lunn [1874] 1900, 10. ${ }^{24}$ Browne and Behnke [1883] 1886, 7.

25 Quoted in Mackenzie [1886] 1891, 87.

26 Shaw, 'A Book for Orators and Singers', in Tyson 1991, 166, refers to Mackenzie's Hygiene of the Vocal Organs (1886) as 'the most interesting English record of laryngoscopic investigation since Mdme. Seiler's', suggesting that she had held the terrain for the intervening quarter century. 
García's interest had been initially limited to the various shapes of the glottal opening in the different registers of the male voice, Seiler extended the use of the instrument into a number of other areas, including study of the female voice. ${ }^{27}$ In particular, she aimed to synthesise a concern for safe singing habits with Helmholtz's experimental interest in the physiology of vowel qualities. Of personal concern were the precise pitches at which breaks between vocal registers occurred, since singers like herself had increasingly exposed themselves to potential injury when stretching the upper range of one register further than it could safely extend. Laryngoscopy enabled a self-discipline in which a singer might coordinate visual observation of the behaviour of the vocal ligaments at various pitch levels with a correspondingly appropriate mode of vocal production. The ability to visualise strain on the vocal ligaments might help a singer to override muscular habits acquired, but no longer consciously noticed, over years of incorrect and damaging voice study. ${ }^{28}$ In fact, laryngoscopic knowledge was explicitly held by Seiler to supplant formal training in song. In a typical historical irony, the way back to the fantasised natural state occupied in the Italian eighteenth century could only be found by stepping through the mirror:

By the kindness of Prof. Helmholtz, I became acquainted with the physical conditions upon which pure musical tones depend, and, after long-continued practice, I succeeded in producing such tones and in making them habitual. Not until I had prepared myself by years of faithful study, and knew the several physical sensations accompanying a perfectly natural musical tone in the different groups, did I begin to observe in myself, with the laryngoscope, the movements in the larynx during the production of tones. In order to draw correct conclusions from such observations, attention must be specially directed to the physical sensations which, in a correct position of the mouth, accompany the formation of a perfect musical tone. For, in using the laryngoscope, the mouth must be opened very wide, and its parts be so drawn aside and so posed that a full view of the glottis shall be afforded. As in this way the resonance and reflexion in the cavity of the mouth become disturbed, it is not possible to distinguish the different groups of tones by their timbre alone. When I succeeded at last in obtaining such command of the parts of the mouth that I could see the whole glottis, I always found the same movements in the

27 E. Seiler 1884, esp. 50-84.

28 E. Seiler 1884, 69-84. Anyone familiar with the history of vocal pedagogy will be sensitive to the tenuousness of any claims about register breaks, with very little agreement on the facts during the decades before and after Seiler's work. See, for example, Davies 2014, 13-40; and G. Bloch 2007. 
formation of the same tones, changing and returning in the same manner. I then sought to make like observation in others, and selected for the purpose persons who never had had any instruction in singing, and whose voices were consequently entirely natural. Professional singers, or such as had received instruction in singing as it is commonly given, I found for the most part to be wholly unfit for the desired observation. For, with a few distinguished exceptions, the voices of such singers are so artificially vitiated that they are no longer in a natural normal condition. The results of the observation of such voices would belong to the class of facts inexactly observed, from which every honest inquirer cannot keep too far aloof. ${ }^{29}$

For Seiler, access to self-present song, to the voice 'exactly observed' and 'natural', could only be gained through the defamiliarising practice of seeing it projected onto a surface beyond the bounds of the person.

If the story of García's eureka moment dramatises a rupture in selfknowledge, a sudden coming into contact with oneself as if for the first time, Seiler's rendering of her own experience in contrast emphasises a more resistant and enduring event, requiring a certain tactus eruditus almost unrecognisable as the same practice. In contrast to García's instantaneous and improbable enskilling in the art of self-observation, Seiler and later laryngoscopists maintained that it could take months to acquire the technique of singing quasi-naturally with the mirror inserted - a considerable factor which set its musical use apart from its clinical use, wherein a relatively brief glance might be enough to reach a diagnosis. ${ }^{30}$ With the introduction of photography of the larynx, or 'photolaryngoscopy', the relative instantaneity of the medical gaze was radicalised. But even in the clinical context, learning to resist the gag reflex (on the part of the singer) and learning to avoid provoking it (on the part of the observer) were demanding enough to motivate the use of a so-called 'LaryngoPhantom', a life-size dummy singer with a realistic oral cavity, for the physician to practise on before working with living subjects. ${ }^{31}$ In short, with laryngoscopy, we are clearly dealing not with a simple and transparent form of knowledge or perception, but with a complex process of training that demanded sustained commitment and some degree of passion on the

29 E. Seiler 1875, 63-5; original emphasis. ${ }^{30}$ See, for example, Mackenzie [1886] 1891, 36-8.

31 The Laryngo-Phantom 'consists of an imitation of the throat, the larynx, and the mouth, and "is intended to familiarise students with as many of the details connected with the use of the laryngoscope as it is possible to learn before the application of the instrument to the living subject." A number of little paintings representing different laryngoscopic appearances may be slipped into this Phantom, unknown to the student, who has to discover what has been done by the usual process.' Behnke [1880]., 77. 
part of its practitioners. If the ammoniaphone promised a short cut to selftransformation, the laryngoscope made the self-transformation all the more plausible by foregrounding the resistances overcome in each minute habitual muscular motion.

One paradox of the laryngoscope noticed in passing earlier bears reiterating here: while it promised wholeness and fluidity to otherwise broken and strained voices, it introduced a disruptive caesura at the heart of the vocal act, marked by the incompatibility of hearing one's voice and seeing it. Or, at any rate, seeing something, though the emptiness of the glottal opening, which García and Seiler were now identifying with voice itself, meant that 'seeing' the voice was really a matter of witnessing a negative space established precisely by the absence of the singer's body. J. Q. Davies aptly describes this phenomenon in terms of an infinite regress in which 'the singer's object of study was moving ever back: from external instruments or mouths in the early century, to the back of the throat, to the glottis, and then beyond, the voice eventually disappearing from ordinary view. ${ }^{32}$ Yet to indicate how laryngoscopy might have rendered the voice strange and exterior is in a certain sense historiographically anticlimactic, given the numerous ways in which the same could be claimed of earlier contexts, including, most famously, Wolfgang von Kempelen's spectacular 'speaking machines' of the eighteenth century. The voice's disassociation has not been a singular event. ${ }^{33}$ Still, the strangeness of the voice that emerged in laryngoscopic perception was in certain respects sui generis. This is perhaps inevitable, given the peculiar fantasy according to which laryngoscopy - less explicitly but just as insistently as the ammoniaphone was imagined to assume the role once played by an antique Mediterranean song foreign to contemporaneous Heidelberg, London or Philadelphia.

The freighted term 'estrangement' hints at a kind of incipient modernism detectable on the scene of laryngoscopy. I am not the first to propose such a link: Tim Armstrong counts the laryngoscope as one among an expanding battery of roughly contemporaneous technologies of 'intervention' - stethoscope, ophthalmoscope, speculum, high-intensity light,

32 Davies 2014, 128. Holly Watkins and Melina Esse (2015, esp. 165-6) present a slightly contrasting view of laryngoscopy, emphasising the reductive folly of trying to identify anything like 'the' voice, particularly when this (necessarily metaphysical) identity is understood as something dualistically severed from the body that produces it. I certainly acknowledge this folly, though the aim of this chapter is primarily to reflect on the fact that such a belief was historically active at all.

${ }^{33}$ Kane 2014, esp. 180-222, vividly elaborates a related point from a much broader theoretical perspective. 
X-rays and so on - which figure in a history of early modernist perception. Invasive and illuminating devices such as these, Armstrong suggests, tend to crop up in a wide range of modernist literary texts that are peculiarly 'characterised by the desire to intervene in the body; to render it part of modernity by techniques which may be biological, mechanical, or behavioural'. ${ }^{34}$ An aspiration to render something 'part of modernity', to make it contemporary with oneself in a manner that cannot be claimed of everyday sensory experience, would seem to describe a central strand of laryngoscopy in García's and Seiler's practice insofar as they were trying to stabilize something so inherently and notoriously fleeting and inaccessible to immediate knowledge. Making the vocal body 'contemporary', visually at hand at roughly the same moment that it is being actualised in song, however, could never have been an intended outcome for anyone who, like Moffat or Seiler, was so explicitly nostalgic for the lost voice of another time and place. It is not possible to conceptualise 'modernity' in this regard as a matter of absolute synchronisation of imaginative and technological resources but rather more as an aspiration constantly and constitutively frustrated.

We may perhaps begin to make sense of this incongruity between an impulse to make 'present' and an apparently countervailing one to look backward to a lost past by recalling how often modernist nostalgias are in fact, ironically, a matter of future orientation. ${ }^{35}$ To be sure, it is not selfevident how we might imagine a sense of futurity in the present context, aesthetically conservative as it appears to have been, but I would propose that one possible, if somewhat unexpected, interpretative context for appreciating such a perspective is the broader study of phonetics, a field I have mentioned only in passing and can do no more than to indicate quite loosely here. Phonetics research, overlapping with Helmholtz's and Seiler's collaboration around 1860, was at the time a new discipline explicitly concerned with foreign vocal sounds, and both abutting the traditional philology and anticipating the unapologetically defamiliarising discipline of modern linguistics. ${ }^{36}$ That Helmholtz and Seiler found themselves making use of the laryngoscope in conjunction with the intensive study of vowel sounds draws this practice into alliance with the grand project, common to every colonial context, of standardising languages according to

\footnotetext{
34 Armstrong 1998, 2-6.

${ }^{35}$ For a recent collection of reflections on this theme, see Clewell 2013.

36 I have addressed the affiliations of music theory, phonetics and early modernism in Steege 2012, 1-6, 178-206 and 229-34. For related explorations, see Brain 1998, 249-84; and Bergeron 2010.
} 
'rational' orthographic and phonological schemes. More interesting than the banal fact of standardisation or rationalisation, though, are the resistant historical circumstances to which these processes responded: namely the vast and rapid expansion of languages and dialects that were coming into contact with one another with increasing intensity in the major metropolitan centres, especially in the later decades of the nineteenth century. Raymond Williams and Michael North have highlighted the significance of the late-Victorian conversion of language from a social custom into a malleable medium within urban immigrant and class-bending cultural environments. In tracing the emergence of linguistic modernism from within the rapidly urbanizing late nineteenth century, Williams has emphasised artists' experience of being

liberated or breaking from their national or provincial cultures ... In this the artists and writers and thinkers of this phase [of modernism] found the only community available to them: a community of the medium; of their own practices. Thus language was perceived quite differently. It was no longer, in the old sense, customary and naturalised, but in many ways arbitrary and conventional. ${ }^{37}$

Though Seiler's and Helmholtz's phonetics research took place near the beginning of this shift and was primarily orientated toward the understanding, appreciation and conservation of a canonical central European musical tradition, it can nonetheless be seen as part of the wider response to a new perception of aesthetic contingency and adaptability, and hence a perceived need to prepare conceptual, technical and cultural resources with which to meet the future emergence of unruly forms of vocal selfpresentation.

In short, if the laryngoscope rendered speech and song elemental, particulate and decontextualised, it did so in affiliation with much broader cultural transformations than the seemingly parochial scenes we have been considering here. It is from this perspective that we might interpret the simultaneously affirmative and disruptive self-fashioning of larynogoscopy (as of the controlled inhalation of ammonia) as a kind of proto-modernist practice. Crowding around the margins of the makeshift, middlebrow operatic community that Shaw derided, we glimpse the nascent image of a reworking of the aesthetic persona common to avantgardes everywhere, despite the constrained moral universe in which these particular behaviours were playing out. Shaw's sketch betokens a wider cultural environment in which, as Williams writes, 'the new relationships

37 R. Williams 1989, 45-6. Also see North 1994, 3-34. 
of the metropolis ... forced certain productive kinds of strangeness and distance: a new consciousness of conventions and thus of changeable, because now open, conventions' ${ }^{38}$ However starry-eyed they may appear in retrospect - or, indeed, to Shaw himself - the transformative cultural force of such scenes was not to be underestimated.

38 R. Williams 1989, 46. 